\title{
POTENCIAL PESQUERO Y ESTUDIOS ECOLOGICOS DE BAHIA MAGDALENA IV. LA DISTRIBUCION Y ABUNDANCIA DE LAS EXISTENCIAS DE PESCADO DE ESCAMA.
}

\author{
Por: \\ Christopher Paul Mathews y Julio Espinoza \\ Ciencias Marinas Vol. 2 Núm.I

\begin{abstract}
RESUMEN
Se efectuó un estudio de las existencias de peces de escama en Bahía Magdalena. B. C. Sur. Se notó que la abundancia fluctúa con la profundidad, zona de mueștra y corı la estación. Se presentan cálculos preliminares de la biomasa de peces en la región. Existen movimientos migratorios muy marcados, en Bahía Magdalena la biomasa invernal es de $\times 4$ más grande que la biomasa veraniega.
\end{abstract}

ABSTRACT

Some results of surveys carried out on the demersal scalc fish of Bahia Magdalena are presented Abunitance fluctuates with depth, are sampled, and season. Preliminary calculations of biomass show that sume very marked migratory movements oscur; in Magdalena Bay, 'Vinter biomass exceeds Summer biomass by $\times 4$.

Durante el año de 1974 se efectuaron dos cruceros en el barco camaronero "Macapule I". Y durante las faenas se recogieron una serie de datos sobre la distribución y abundancia del pescado de todos tipos dentro de la zona de Bahía Magdalena. El barco tenía 72 pies de eslora y $2 \mathrm{~m}$ de calado; por estas razones estaba limitado su acceso a los dos vasos principales de la zona (Bahía Magdalena y Bahía Almejas). Las capturas se efectuaron hasta en aguas de 24 brazas en Bahía Magdalena y a 14 brazas en Bahía Almejas, siendo éstas las profundidades máximas en las dos Bahías; los lances que se llevaron a cabo fueron también en las aguas de 2 brazas, pero la zona de 1-2 brazas se muestré incidentalmente y la de $0-1$ no se muestreó.

Los dos cruceros se realizaron del 7 al 20 de Febrero y del 20 al 27 de Agosto respectivamente, $y$ se realizaron 58 y 38 lances respectivamente. En el crucero de Febrero se usó el equipo de cuatro redes, mientras que en Agosto se usó el equipo de dos redes.

Este último equipo llevaba redes con traya de 64 pies, y calculamos que se pescó en ese crucero, en una franja total de $30 \mathrm{~m}$ de ancho. Durante el primer crucero las cuatro redes fueron más pequeñas de 35 pies de traya cada una; probablemente pescaron en una franja de más o menos 30 metros; o sea, para este barco, el área pescada con los dos equidos fue aproximadamente la misma. Para poder comparar las capturas de los cruceros en otras zonas, se convirtieron los datos de captura por lance ( $\mathrm{kg} /$ lance) a captura por hora de pesca $(\mathrm{kg} /$ hora). La captura, en $\mathrm{kg} /$ hora se convierte en la abundancia mediante las ecuaciones siguientes:

Si ponemos $K=$ abundancia $(\mathrm{kg} / \mathrm{ha})$ (i)

$K=\frac{\text { C. }(1853) \times \vee \times D}{10,000} \times \frac{1}{V} \cdots \ldots .$. (ii)

donde $\mathrm{C}=$ captura en $\mathrm{kg} / \mathrm{h}$ ora.

$1853=$ factor de conversión ae millas náuticas a metros.

$v=$ velocidad en millas náuticas por hora.

$D=$ anchura de la franja de fondo barrido por las dos redes juntas durante la pesca de arrastre. 
$V=$ la vulnerabilidad de los peces a las redes.

$10,000=$ factor de conversión de metros cuadrados a hectáreas.

Durante este trabajo se notó cierta variación de la velocidad de arrastre que variaba de 2.3 hasta 3.4 nudos, con una velocidad normal de 3.0 nudos.

El valor de la vulnerabilidad $V$, es descanocida pero para pescado de escama es usual asumir que el $50 \%$ de los pescados escapan nadando debajo de la traya, arriba de la red, o por los lados de ella.

Las áreas de las diferentes zonas batimétricas de Bahía Mugdalena y de Bahía Almejas se calcularon por planimetría, basados en las cartas navales publicadas para la zona.

El control de profundidad durante los lances fue generalmente menos de $10 \%$, pero en aguas muy bajas fue menos preciso.

\section{RESULTADOS}

La Fig. I muestra la distribución batimétrica de las abundancias de los pescados de escama en Bahía Magdalena y Bahía Almejas durante el crucero de Febrero. Se ve que no hubo gran diferencia en Bahía Magdalena entre las capturas diurnas y nocturnas; por consecuencia se pueden tratar los datos igualmente $y$ sin respeto a la hora del lance.

Tampoco parece variar la abundancia con la profundidad, por lo menos entre 3.5 y 21 brazas, que fueron los límites de profundidad para el crucero de Febrero. La abundancia promedio en $\mathrm{Ba}$ hía Magdalena fue entances de 29.65 $\mathrm{kg} / \mathrm{ha}$

- Se nota en la Fig. I que la distribución de la abundancia en Bahía Almejas es muy distinta. Existen dos zonas batiméticas: de $3-8$ brazas donde la abundancia es baja, y de 8-11 brazas, donde es mucho más elevada.

Unicamente se efectuaron 4 lances nocturnos en Bahía Almejas, pero todos dieron abundancias mucho más elevadas que las encontradas en el día (por ser muy pocos los datos nocturnosl. Por carecer de datos nocturnos se asume que los datos se pueden juntar sin referencia a la hora del día. Si este procedimiento lleva hacia un error, tenderá a ser una subestimación, puesto que el pescado parece ser más vulnerable de noche y puesto que los datos son mayormente diurnos. Las abundancias promedio son de $44.5 \mathrm{~kg} / \mathrm{ha}$ para las aguas bajas, y de $164.7 \mathrm{~kg} / \mathrm{ha}$ para las más profundas, en la zona de Bahía Almejas.

La Fig. 2 presenta la distribución batimétrica de las abundancias encontradas en Agosto. Se ve que existió una situación diferente en las dos bahías: las abundancias en Bahía Magdalena que llegaron a $40 \mathrm{~kg} / \mathrm{ha}$ en Febrero, llegan hasta casi $300 \mathrm{~kg} / \mathrm{ha}$ en Agosto (en dos estaciones): las 25 estaciones localizadas en Bahía Magdalena, rindieron abundancias de $90-300 \mathrm{~kg} / \mathrm{ha}$. La abundancia promedio fue de $125.4 \mathrm{~kg} / \mathrm{ha}$, en lugar del valor de $29.7 \mathrm{~kg} / \mathrm{ha}$, que se encontró en Febrero.

Existe una pasible variación en las aguas muy bajas (3.0 brazas) en donde las abundancias tal vez sean menores, pero los datos son insuficientes. No existe indicación cualguiera de diferencias entre capturas diurnas y nocturnas. Siende pocos los datos se han ignorádo estas indicaciones.

En Bahía Almejas, las abundancias altas de la zona profunda continúan, pero se extienden también en las aguas menos profundas; la abundancia promedio es de $186.2 \mathrm{~kg} / \mathrm{ha}$.

La Tabla 1 presenta estos resultados, con los cáleulos del área total, y los valores de la biomasa total calculada para cada Bahía.

La razón de las biomasas en las áreas estudiadas de Bahía Magdalena y Bahía Almejas es de $2.07: 1.00$, en verano o sea, de 2 : 1; mientras que en invierno, la ración de las biomasas fue de $1,723: 1,725$, o sea de $1: 1$. Es decir que en el invierno Bahía Magdalena, en una superficie dos veces más grande contenía la misma biomasa que Bahía Almejas. La relación de las biomasas en Febrero debió ser más favorable para Bahía Almejas puesto que se excluyeron de los cálculos las aguas de 2-3 brazas debido a la carencia de datos. Asumiendo que tienen la misma abundancia que 


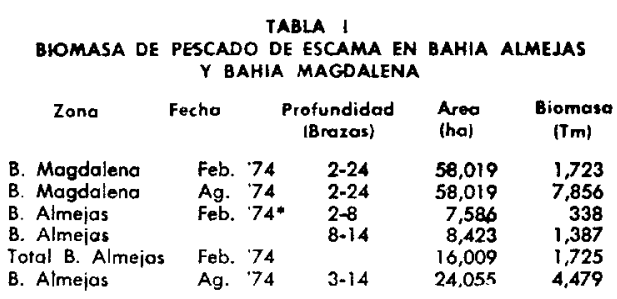

- Excluyendo aguas cie 2-3 brazas. Incluyendo estas aguas el Grea sube hasta 15,632 has $v$ la biomosa hasta $690 \mathrm{Tm}$. En este caso lo biomasa totalasciende a 2,083 $\mathrm{Tm} ;$ y el frea total, hasta 24,055 has.

las aguas de 3-8 brazas resulta la relación de las biomasas ser: 1723 : 2089. o sea 1 : 1.21 .

En el verano la situación cambia: Bahía Magdalena, con el doble del área de Bahia Almejas, contiene 7,856 Tm de peścado de escama contra 4,470 Tm; o sea las áreas siguen en razón de 2 : 1 mientras que las biomasas tienen una razón de 1.75 : 1. La diferencia entre estas dos últimas razones probablemente no es significativo; o sea la biomasa total es entonces resultado principalmente

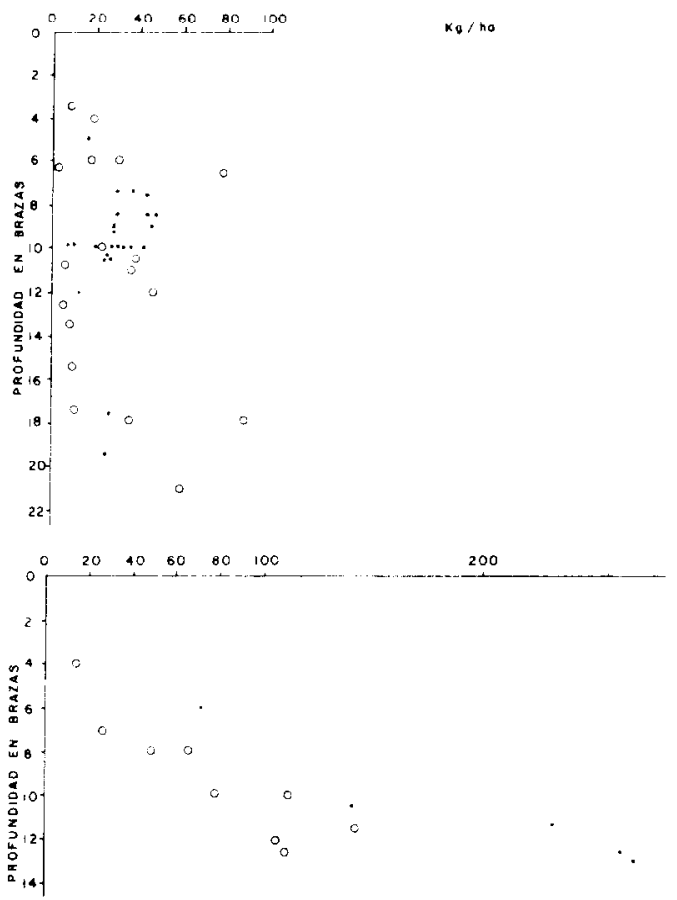

Fig. I Distribución batimétrica de abundancias ( $\mathrm{Kg} / \mathrm{ha}$ ) en Bahia Magdalena (arriba) y Bahía Almejas (abajo).

- Muestra diurna. Muestra nocturna. del área disponible en las Bahias Icon excepción quizá, de las aguas más profundas).

Al mismo tiempo las abundancias y las biomasas han subido en todas las zonas en Agosto comparado con Enero; en el caso de Bahía Magdalena el incremento es particularmente fuerte, con un cambio de abundancia promedio de 29.7 hasta $135.4 \mathrm{~kg} / \mathrm{ha}$, y con biomasas cambiando de 1,723 hasta 7,856 $\mathrm{kg} / \mathrm{ha}$; estas cifras corresponden a un factor de $\times 4.6$. Para Bahía Almejas la $51-$ tuación es menos clara puesto que no se efectuaron lances en aguas de 2-3 brazas en Febrero, pero ignorando este defecto, la razón de las biomasas es de $1,725 \mathrm{Tm}$ en Febrero y 4,479 $\mathrm{Tm}$ en Agosto, o sea de 0.38 : 1 ; si se asume que, en las aguas de $2-3$ brazas hubieron abundancias iguales a las encontradas en aguas de 3-8 brazas esta razón es de $2,048: 4,479$, o sea de $0.47: 1$. Esto corresponde a un incremento por un factor de $\times 2.1-\times 2.6$.

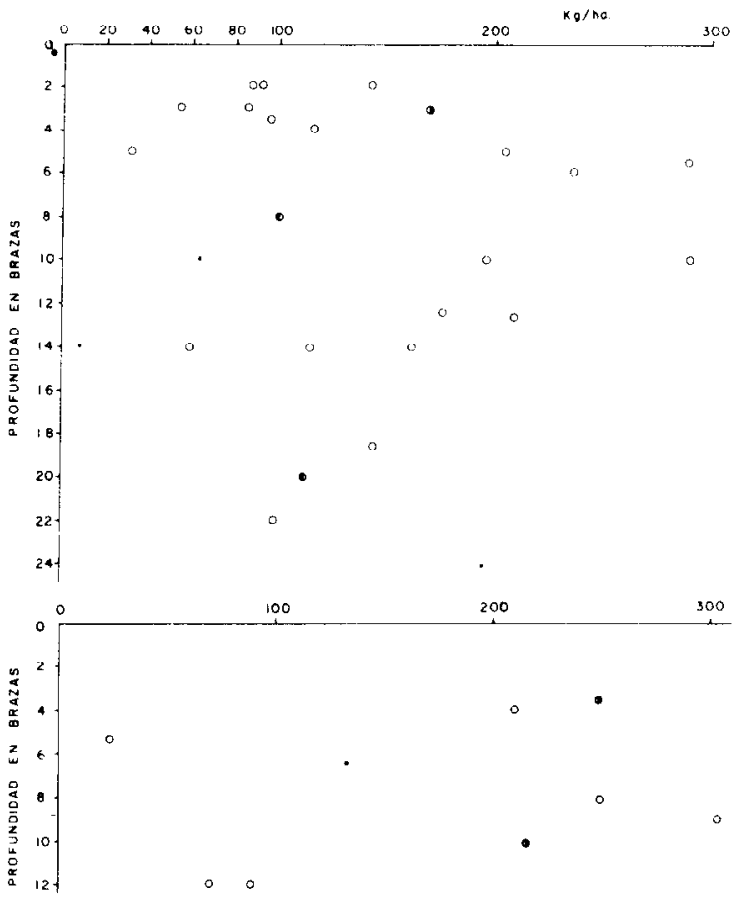

Fig. 2 Distribución batimétrica de abundancias ( $\mathrm{Kg} / \mathrm{ha}$ ) en Bahia Magdalena (arriba) y Bahía Almejas (abajo).

- Muestra diurna. O Muestra al anochecer.

- Muestra nocturna. O Muestra al amanecer. 
Las causas precisas de estos cambios todavía son desconocidas. En invierno ciertas especies salen de las bahias y suben nacia los esteros, Micropogon estenes, denominada localmente boca dulce, sube a los esteros en Noviembre-Diciembre y comienza a bajar en Febrero; parece ser que en ese período se en. cuentra en condición de desove. En Agosto se encuentra en las bahía en abundancias más elevadas que en invierno, $y$ en gónadas que indican una recuperación lenta de condizión. Menticirrhus undulatus y Umbrina roncador son casi ausentes de las banias en Febrero; se encuentran en abundancias más elevadas en Agosto. Otras especies como el botete, Spharoides lobatus y quizás el lenguado Paralichthys californicus, son menos abundantes en Agosto que en invierno.

La composición específica de las dos bahías también es distinta: Eucinostomus argenteus, capturado en muy grandes abundancias en Bahía Almejas, se encuentra siempre en abundancias más bajas en Bahia Magdalena.

En un principio la distribución de las y hasta ser completado este análisis se debe ser sujeta a un análisis detallado especies de escamas en ambas bahías podrán definir las causas de las diferencias observadas.

Estos resultados se complementarćn en la luz de los trabajos planeados para los meses venideros. Entre tanto es claro que la biomasa de pescado de escama fluctúa ampliamente en diferentes estaciones $y$ es menester un conocimiento profundo del cuadro ambiental. Para poder tener estos resultados en una perspectiva correcta; también será necesario considerar las especies principales que contribuyen a la biomasa de pescado de escama, puesto que van a tener diferentes comportamientos.

\section{AGRADECIMIENTOS}

Se agradece la colaboración de los pescadores de la Cooperativa Isla Macapule en la realización de este trabajo, al cual fue presentado como ponencia en el $V$ Congreso Nacional de Oceanografía celebrado en Guaymas, Son., en octubre de 1974.

Quiero agradecer la cooperación de los pescadores de la Cooperativa "Isla Macapule" de Guasave, Sin. y al Capitán Miguel Evaristo Cárdenas del barco Macapule I. También agradecemos la cooperación de la Secretaría de Recursos Hidráulicos con quien se efectuaron estos trabajos bajo contrato can la Dirección de Acuacultura. También agradecemos la ayuda que nos prestó el P.O. Javier Amador Buenrostro Residente de la Dirección de Acuacultura en La Paz, B. E. Sur, y al Ing. Sonín Pérez Pérez Director de la Escuela Tecnológica Pesquera de San. Carlos B. C. Sur y al Ocean. José Pérez Higuera Sub-Director de la misma. También queremos reconocer la coopeación y ayuda del Biol. Manuel Flores Villegas Jefe de Pesca en Baja California Sur; al comandante del Sector Naval de Puerto Cortés, B C. Sur Vicealmirante Argudín, y a todos los otros oficiales del Gobierno Federal que nos facilitaron los trabajos en esas zonas. 